\title{
Is there a role for Mobiles to support Sustainable Agriculture in Africa?
}

\author{
Simon Batchelor, Nigel Scott \\ Gamos \\ Reading, UK
}

\author{
Alvaro Valverde Lopez \\ Oxfam GB \\ Oxford, UK
}

\author{
Cristina Manfre \\ Cultural Practice, LLC \\ Bethesda, USA
}

\author{
David Edwards \\ International Sustainability Unit \\ London, UK
}

\begin{abstract}
In this paper we present the findings of an in-depth consultation with 50 experts in Agriculture and ICT. The qualitative study explored how ICTs, particularly mobile phones, could be used to accelerate the uptake of Sustainable Agriculture in Africa. Situating the responses in a broad literature review, the data and subsequent analysis paint a broad picture of a converging landscape of agriculture and ICTs. Its main conclusion is that the application of ICT (including mobiles) in agriculture is sustainability neutral; that is to say that ICT is equally applicable to the expansion of conventional, high external input dependent agriculture, or to the development of more sustainable, agro-ecological approaches. The rapid growth in mobile phone penetration in developing countries therefore presents a significant opportunity to help underpin a transformation in agricultural development and food systems, but without a co-operative and focused effort across different stakeholders groups - local actors, private sector partners, donors, expert institutions, and national governments - the potential for mobiles to empower sustainable agricultural development is unlikely to be maximized. The paper outlines the major assumptions behind these statements, and presents a conceptual model for understanding the flow of information through the agriculture sector.
\end{abstract}

Index Terms - ICT, sustainable agriculture, Sub-Saharan Africa, mobile phone

\section{INTRODUCTION}

The data presented in this paper draws on literature and an in-depth consultation with 50 experts in Agriculture and ICT. This was conducted as a part of a wider strategic set of actions taken by the International Sustainability Unit of His Royal Highness Prince Charles, and Oxfam GB, with support from the GSMA.

The interviews focused on how mobile technology services could be used to strengthen sustainable agriculture. The interviewees included programme directors and researchers from donor agencies and NGOs engaged with various aspects of sustainable agriculture, ICT for Development (ICT4D), and agricultural extension, alongside leading actors currently operating mobile for agriculture (M-Agri) projects and interventions (including information service providers, social networks, extension service providers, value chain information and transaction services), and mobile network operators (MNOs).

All agricultural practice now aspires to be 'sustainable', so the term tends to mean different things to different people. In this paper we take a fairly rigorous view of sustainability, based on building soil fertility, minimising the use of nonrenewable external inputs, reducing water, energy, biomass and nutrients losses, and reducing environmental pollution. Such approaches preserve environmental and food crop biodiversity, respect animal welfare, enhance the health of local populations and promote social and gender equity.

The research was anchored in a pro-poor approach to agricultural development, and explicitly identified smallholder farmers as the target group. The definition of a smallholder farmer differs between countries and between agro-ecological zones; in favourable areas of sub-Saharan Africa with high population densities smallholder farmers often cultivate less than 1 ha of land, whereas they may cultivate 10 ha or more in semi-arid areas, or manage 10 head of livestock [1]. Common characteristics are low access to technology, a reliance on family labour, and engagement in farming as only one of a diverse range of income generating activities.

The paper starts with an overview of current thinking on agricultural innovation, approaches to increasing productivity and profitability of smallholder agriculture, and the extent to which mobile technology has played a role to date. It then goes on to present the findings from the expert consultation exercise. In response to key themes emerging from the consultation, an actor-centric model was developed, which describes the large number of actors and information flows associated with a farmer in his or her community. Finally, the paper discusses findings from the consultation in the context of current trends within the mobile industry.

\section{THE AGRICULTURAL ENVIRONMENT}

\section{A. Recent Trends}

After two decades of declining investment, overseas development assistance to the sector has been on the rise again 
[2]. Two principal factors lie behind this trend. One is an economist's view that agriculture is a key pro-poor strategy for economic growth. The second is a concern for food security, based on a recognition that natural resources are limited, farm sizes are getting smaller, populations are increasing (the population of Africa has quadrupled since the 1950s), and that climate change and water scarcity threaten the security of basic food production.

While there is increasing agreement around the need to enhance resilience and respond to climate change within agricultural practice, there is not yet an equivalent recognition of the relevance of a truly sustainable approach. There is broad agreement that agricultural productivity in many developing countries needs to improve, although some argue that from a global sustainability point of view, policies targeting increased production are aiming at the wrong goal. For example, Scherr et al. [3] argue that redistribution of traded foods and reduction in wastage can go a long way to meeting growing food demands. The ways in which agriculture should be developed remain hotly debated. Some argue for more industrialised and intensive forms of agriculture, while others believe that more ecological, decentralised, community-based approaches are essential to any long-term solution [4].

Three key sets of actors influence the international agricultural agenda, and the dynamics between them are shifting under the strengthening influence of globalisation:

- Governments: A growing number of state and national governments in Asia and Africa have started to adopt principles of sustainability within their agricultural policies e.g. the Comprehensive Africa Agriculture Development Programme (CAADP) [5]. However, it remains contested as to what extent these principles are working their way into local policy structures.

- Corporate Sector: The continuing trend towards globalisation in food and agriculture markets has led to some dramatic shifts in the ways in which agricultural policy and practice can be influenced. Once on the sidelines of the agricultural debate, actors in the corporate sector are now finding themselves with increasing power to do both "good" and "ill" and are looking towards developing countries for growth. The corporate sector's growing interest in the sustainability of agriculture is driven chiefly by the need to mitigate risks to production security from environmental change.

- Farmers: Caught between these shifting dynamics, smallholder farmers have their own priorities too, and these primarily relate to risk mitigation. Subsistence farmers tend to be particularly risk averse, for the simple reason that they do not have the economic resources to deal with unpredictable farming outcomes. This sensitivity to risk can serve as either a driver or as a barrier to the sustainability agenda, dependent on the solutions that are made available to the farmer.

Accompanying recent trends is an awareness of the need to close the gender gaps that limit agricultural productivity and development outcomes. Women are important actors in agriculture - they contribute as farm leaders, unpaid family and wage workers, traders and entrepreneurs. For sub-Saharan Africa, women make up $48 \%$ of the agricultural workforce (the highest figure is $65 \%$ in Mozambique), and the agriculture sector provides $65 \%$ of employment for women [6]. Relative to men, women tend to have less access to productive resources. And despite their prominence in the sector, women are both overlooked and underserved by service providers, extension officers, buyers, and other agricultural actors. Such gender inequity creates a scarcity cycle: less resources, less access to resources, less access to advisory services, less access to markets, leading to fewer resources. Where gender inequity exists, women may also have less access to mobile phones, as a result not only of economic constraints, but also of cultural and literacy constraints [7]. With this in mind, any services, whether face-to-face or using mobile technology, need to be designed specifically with women in mind.

\section{B. Knowledge Based Assistance}

Agricultural extension systems were originally created by governments to disseminate knowledge on agricultural management practices amongst farming communities. Yet the nature of these services has changed dramatically over the last 20-30 years. Across a number of countries, the quality and availability of services has suffered a huge decline as governments have withdrawn investment [8]. At one time, many developing countries had, on average, one government extension agent for 300 farmers, yet today there can be as few as one for every 1,500-3,000 farmers. This is well below the FAO recommended ratio of 1 officer for every 400 farmers.

Although a number of new entrants have emerged, farmers have been left with a somewhat patchy array of potential advisors and without clear access to trustworthy advice. Governments are now beginning to re-engage and as extension services reshape themselves and learn from past mistakes, professionals have realised that the simple delivery or dissemination of information is no longer enough. Swanson \& Rajalahti [9] discuss how extension approaches have changed over the years through the four major paradigms of agricultural extension:

- Technology transfer;

- Advisory services;

- Nonformal education;

- Facilitation extension.

Current practice is based on participatory learning, in which the extension worker facilitates learning and acts as a 'knowledge broker'. It is no longer sufficient for a trained agriculturalist to present farmers with a solution to their problems. Methods must involve the co-construction of knowledge, drawing on the farmers' own experience as well as the formalised knowledge of an expert worker. As a result, modern extension practice recognises that farmer field schools, farmer-to-farmer extension and other farmer-centric processes must be at the core of effective agricultural development. Service providers today are looking to create new platforms for the co-construction of knowledge specific to the farming context, with an emphasis on the use of local knowledge and 
farmer-to-farmer learning. Furthermore, modern extension systems continue to grapple with how to extend the reach of their services to women via methods and approaches that tap into women's social networks, account for restrictions on their time and mobility, and are designed for differing levels of education and literacy [10].

One of the interesting new roles to have emerged with particular relevance to M-Agri is that of the "infomediary": an agent able to use ICT-based services to access and share information on behalf of intended beneficiaries. Initially, infomediaries were librarians or telecentre managers, but as ICT applications have continued to diversify, so have the roles of infomediaries. Grameen Community Knowledge Workers ${ }^{1}$, for example, operate as generalist extension workers who, rather than disseminating information, are able to co-construct knowledge by combining local knowledge with more general insights from global knowledge bases. As extension services diversify it is important to ask how a farmer might navigate them successfully, as it is not always easy to assess trustworthiness and relevance. In the same way that the poor may have lower levels of literacy due to a lack of formal education, so too they may have lower levels of "information capability", which can make them particularly vulnerable to aggressive marketing and to being co-opted into commercial relationships without a full understanding of the implications.

The potential role of ICT in supporting this process has only become more evident recently, and this opens up new opportunities to underpin the sort of 'facilitative extension' that can be so effective in shifting practice amongst farmers.

\section{CONSUltation RESPONSES}

\section{A. Sustainable Agriculture}

Sustainability can mean different things to different people, and this creates a host of challenges for the development and categorisation of information services. One view of sustainability was that "it's what works" and included practices that have successfully been incorporated by farmers into local conditions through processes of innovation and refinement. A similar concept was that of "local knowledge" - sometimes practices are called organic but actually they are simply local techniques using local inputs. Key to this idea is the sharing of knowledge among farmers, and adaptation and local contextualisation of knowledge.

Small holder farming is already low input. Poor smallholder farmers tend not to use chemical inputs, although this may be mainly for economic rather than ideological reasons e.g. only $13 \%$ of smallholder farms in Tanzania used chemical fertilisers, and $14 \%$ used insecticides and fungicides [11]. However, low input is not synonymous with sustainability. For example, within the organic sector, it was

\footnotetext{
${ }^{1}$ Grameen recruits and trains rural community members as Community Knowledge Workers (CKWs) who act as "trusted intermediaries" in their communities in rural Uganda. They use basic smartphones loaded with an application that helps them provide information services to their fellow farmers.
}

observed that some farmers won certification just because they were not using inputs, yet if they fail to manage the land (e.g. with composting) then the land will degrade and the agriculture cannot be regarded as sustainable. Organic low input certification alone does not give the farmers the knowledge and skills to manage the land sustainably, and it was acknowledged that the sector was missing an opportunity to actively promote truly organic practices rather than simply providing a certification service. Achieving sustainability is knowledge intensive.

The question remains as to the role that technology can play. Currently, there is a strong consensus that face-to-face contact is crucial to building knowledge [12]. At the field level, intermediary actors are required to facilitate conversations around sustainable agricultural approaches, to enable the coconstruction of knowledge, and to encourage adoption. To date, mobile technology platforms have not been able to underpin such forms of engagement by themselves, however there is a clear opportunity for mobiles to play a supportive role.

\section{B. Facilitating Access to Knowledge}

Field level actors, including extension agents and knowledge workers, are still needed to facilitate informed conversations, to enable the co-construction of agricultural knowledge, and to encourage the adoption of sustainable farming practices. These agents of change not only need political support towards these ends to be truly effective, but also require funding and professional support. Mobile phones can be an effective tool to support their professional development.

\section{1) Willingness to Pay}

Even though there is plenty of evidence from farmers that access to information can increase profits, small farmers may not be willing to pay for information services. The eSagu service $^{2}$, for example, initially charged a monthly fee but saw the number of subscribers drop over three years, even though evaluations showed that farmers made significant financial savings thanks to the service. Uncertainty of farmers' willingness to pay has been identified as a key factor in the design of mobile agriculture services [13].

There are several factors involved. First, farmers are accustomed to getting agricultural information for free (e.g. weather forecasts), second, they prefer to learn from each other (power of progressive farmers, demonstration farms, exchange visits), and thirdly, within the broader context of household information needs, agriculture is not regarded as a priority [14]. Successful business models to date tend to generate revenue from elsewhere. For example, although Grameen CKW does charge users a fee for the service, they generate additional revenue through related services, such as surveying farmers for third parties. There is a tendency to expect that the costs of an advisory service will be built into a particular value chain, or that they will be cross subsidized by other extension services. For these reasons, models where the cost of information is

\footnotetext{
2 eSagu provides a quality personalized agro-advice to the farmers starting from pre-sowing operations to post-harvest precautions in India.
} 
subsumed into the price of a telephone call or some other service tend to be more acceptable to farmers. However, the explosion of mobile money services and the movement towards digitising financial transactions could facilitate greater adoption of pay-for-fee agricultural advisory services in the near future.

An interesting example of a successful information service is IKSL in India, a joint venture between Bharti Airtel and IFFCO. This service attracts new customers to the Airtel network by providing a branded "green SIM" card. It offers 5 free voice messages a day with partially localised agricultural content. In addition, farmers can access an agricultural call centre (local call charges) and enjoy reduced call charges to other farmers who own a "green SIM" card. The service has 3 million registered SIM card holders and 1.5 million active users, suggesting it is valued by users.

It is important to acknowledge that conflicts of interest concerning both access and content can have implications for revenue generation. For example, advertising attached to information services offers the potential to increase sales and revenues for agro-industries. However, there arises a clear conflict of interest when such services incorporate advice on sustainable agricultural practices, which would probably discourage users from purchasing the products or agricultural inputs promoted by potential advertisers.

\section{2) Gender Considerations}

Constraints to the effective use of mobile phones in providing equitable access to information on sustainable agriculture include access to mobiles (including issues of culture, cost and technical literacy), and a lack of services designed to meet the needs of women. Mobile phone ownership among women is lower than among men [7], but interviews suggested that closing the mobile phone ownership gap may not be sufficient to ensure that women will benefit from M-Agri services.

New research on the mobile space reveals that women prefer convenience, reliability, security, and privacy in their mobile products and agent networks [15]. This is because they correspond to a number of gender-based constraints that affect women, including limitations on mobility and time. Some MNOs have begun to respond by modifying their tariffs plans in response to women's preferences, tailoring marketing, and improving the placement of agents.

An inclusive M-Agri system will therefore need to consider how the characteristics above are embedded within the network of actors and services delivered to women. At the same time, the preference for face-to-face engagement, even among women farmers, will continue to require thoughtful approaches to ensuring that extension and advisory services are inclusive of women. These approaches are well-known, although perhaps not well-practiced [15].

\section{3) Partnerships}

One of the clearest lessons from ICT4D to date is that partnerships are the foundation upon which any successful initiative must rest. This was strongly endorsed by the respondents, who noted the importance of partnering with local and regional farmer organisations when rolling out new initiatives. This includes local NGOs and farmer or producer groups; producer groups lie at the heart of farmer-to-farmer exchange. They also felt there was more value in strengthening regional rather than national policymaker networks. Producer groups were emphasised as vital sources of information to guide national policymaking, particularly where the M-Agri system is capturing and documenting farmer practices. Similarly, local NGOs can also play an important role in capturing local, on-the-ground expertise in rural development and agriculture.

There was an expressed need for on-going funding of MAgri service development, but this appeared to be appealing to investors rather than donors. It was observed that few ICT conferences have showcased anything that is yet working at scale. At the same time, lack of investment was regarded as a barrier to making the 'breakthrough' to achieve scale. A funding gap appears to exist between the large amounts that venture capitalists and donors want to invest (typically between 5 and 50 million dollars), and the relatively modest amounts needed by local companies developing mobile services (typically hundreds of thousands of dollars).

Scale is also an issue in attracting the support of MNOs. MNOs will tend to approach app developers only once their apps are operating at scale. Furthermore, they then want exclusivity. App providers, on the other hand, are keen to broaden access to their services as widely as possible to optimise their reach and commercial success. As a result, a latent tension is often found between the two.

At a higher level, initiatives to promote public-private partnerships (for example, the UN Global Compact) are starting to emerge, however there is a potential need for more focused convening of practitioners within the M-Agri space, to support the further establishment of cross-sector partnerships.

\section{A Changing Technology Landscape}

The next 5-10 years are predicted to see a significant shift in the way that information is used and flows, with one of the leading trends being a rise in the predominance of data services. Although studies to date suggest that awareness and use of data services has been limited [16], [17], things are changing. In support of this claim, the GSMA recently published a report predicting that the majority of phone revenues will be data-led by 2018 [18] and Safaricom in Kenya issued a press release saying that 90 percent of revenue will be from data by 2016.

The customer base of MNOs offers particular value to the development of M-Agri services, as this represents real marketing power. MNOs also have a strong distribution and agent network that can demonstrate to farmers how to use new services. Tigo Millicom in Tanzania, for example, is currently training their rural sales agents to provide their new agricultural service. Having said this, respondents noted that this current advantage could change quickly with the growth of social media. MXit apparently has 45 million users, mainly in Africa, and it was hypothesised that a service launch via a viral message on this platform could reach a substantial number of people. With such social media platforms becoming increasingly ubiquitous, it is possible that the pivotal relevance 
of MNOs to the development and spread of M-Agri services may have already peaked.

While some telecoms providers have suggested that these shifts may be of limited applicability to the poor, current trends seem to indicate otherwise. The following examples, shared by respondents over the course of the interviews, offer some interesting indications of current shifts in technology use and information flows amongst those at the bottom of the pyramid (BoP):

- A number of startups are now providing low cost communications to farming communities, for example Village Telco operates a Wi-Fi network using "unlicensed" bandwidth. This could promote farmer to farmer networking within a homogenous agricultural zone.

- There are pilots using new spectrums, such as TV White Spaces, that can facilitate growth in low cost broadband access. Google will be jumping into this imminently.

- Low bandwidth data services, for example, Fonetwish ${ }^{3}$ and Nokia Life 4 , render unstructured supplementary service data (USSD) data exchanged over GSM network to provide the user with a graphical experience.

- Services such as biNu ${ }^{5}$ interpret smartphone data and send it to feature phones over low bandwidth, giving users access to the Facebook experience on a cheap phone.

- Cheap smartphones are emerging, currently at $\$ 125$, but with the price in decline. However there is also a rapidly growing second hand phone market, with 45 percent of phones in use in Africa currently second hand. If Europe and America start getting rid of their smartphones they could end up in various developing economies at an even lower price point.

- Uganda already has $4 \mathrm{G}$, albeit not in rural areas, making evident the potential for leapfrog advances in technology uptake.

- Opera Mini Browser, which shrinks webpages by up to 90 percent before they reach a phone, is being preloaded onto the new generation of Indian smart phones.

- The advent of data-based telecoms could enable cheap voice calls, including Skype-like services and "special communities of interest".

\footnotetext{
${ }^{3}$ Fonetwish is a solution for users to access Facebook without a mobile data plan. It uses a "USSD-based interactive solution" to allow users to access the social networking site.

${ }^{4}$ Nokia Life is an SMS and USSD based, subscription information service designed for emerging markets which offers a wide range of information services covering healthcare, agriculture, education and entertainment.

${ }^{5} \mathrm{biNu}$ is an app that runs on a wide range of mass-market mobile phones, providing super-fast and affordable access to web-based apps and popular Internet services
}

- Instant messaging and voice communication are likely to become increasingly available at low cost using services such as MXit and WhatsApp.

- The expansion of mobile enabled payments and other financial services, such as MPesa, provides an enabling environment for other transaction based mobile services.

\section{ACTOR-CENTRIC MODEL}

To date most work concerning ICT in the agriculture and rural livelihoods space continues to focus on the impact of ICT (including mobile services) on economic or productive output, which has been considered to be the touchstone of development practice. However some have gone beyond economics to consider benefits in terms of social impacts on livelihoods [14], [19].

Authors have observed that early work with ICT4D focused on potential applications of technology, based largely on pilot projects. More recently, authors have turned their attention to exploring ways in which ICTs can contribute to reducing poverty, responding to calls to provide evidence of the impact of ICTs. All of this is somewhat techno-centric, focused on the function and value that technology brings, and some authors have called for a more information-centric approach to working with ICTs [20]. It is, therefore, interesting to note that one of the key findings from the consultation was that sustainable agricultural practice, especially agro-ecological approaches to sustainable agriculture, is particularly knowledge intensive. This suggests that any initiative to promote the adoption of sustainable agriculture needs to focus on knowledge. To some extent this is reinforced by another theme emerging from the consultation, which is that ICT is essentially agnostic - it does not inherently lend itself to one approach to agriculture or another - ICT can only be of value in the adoption of sustainable agriculture if it is actively employed to do so by stakeholders in the agricultural sector.

Couple this with the finding that face-to-face contact with extension workers and with peer farmers is regarded as crucial to the adoption of innovative practice. The hypothesis is that experts, such as extension workers, introduce new information into a community of practice (such as a farmers' group). It is then the members of the group who test that information, put it into practice, discuss it and over the course of time distil it into local knowledge that has been refined and adapted to become appropriate to the local context and conditions. There are two key factors here: a source of information, and a process of peer to peer knowledge exchange. 
How then can we conceive of these aspects of information, knowledge, and dialogue that are key to promoting sustainable agricultural practice, along with the realities of value chains and community networks that make up the context within which farmers find themselves? Building on previous work in agricultural extension [21], we developed an actor centric model. Who does the farmer interact with and who has a role farmer sharing can be facilitated by professionals.

The telecoms industry is not specifically represented on the model, simply because they can be regarded as a conduit or channel through which other actors, such as extension agents, suppliers, or weather departments can reach farmers. This is not to demean their importance as an actor in the process of making services available to farmers.

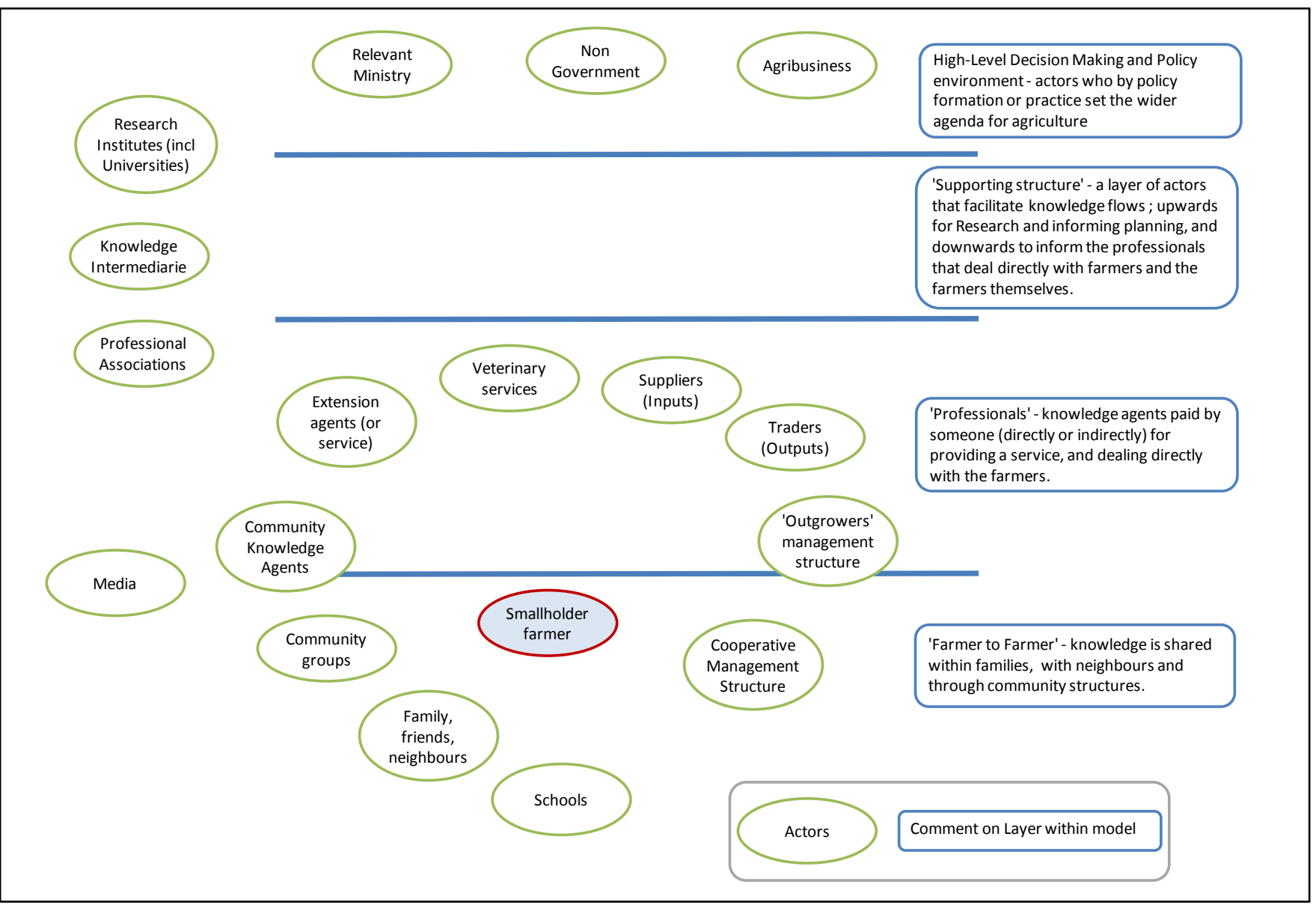

in the value chain? In the initial model, we did not seek to show the information flows between the actors but mapped their position on the diagram with some approximation to the 'distance' of their link to the farmer. This suggested that there were four layers of actors:

- High-level political economy;

- Supporting structure;

- Professional input into farmer exchanges;

- Farmer-to-farmer engagement.

We have put 'schools' within the farmer-to-farmer layer, as information brought home by children can be shared with their parents - this could be elevated to the 'professional' layer if the school had an explicit strategy to build local agricultural capacity. Similarly, we have put 'media' on the border of farmer-to-farmer and professionals, since the emerging cadre of radio chat shows and farm TV makeovers, such as Mediae's Shamba Shape-Up on Kenyan TV, shows how farmer-to-

\section{DISCUSSION}

\section{A. Co-creation of Knowledge and Face-to-Face Communication}

A key theme emerging from the consultation was the idea that face-to-face and farmer-to-farmer co-construction of knowledge are important features of the process of agricultural innovation and adoption. Alongside an understanding of preferences for information type, it is vital to explore the most preferred forms of information delivery. A number of recent studies of poor farmers in both Africa and Asia have found that face-to-face communication trumps all other modes [12]. Where pricing allows, simple voice calls are also an important source of information exchange. Indeed, voice calls by mobile phones easily outrank other means of sourcing information.

This is particularly true in the case of sustainable

Figure 1 The Actor-centric model, outlining key actors to come into contact with the farmer as well as the kinds of information flows that might operate between them 
agriculture, which compared to high input forms of agriculture, is particularly "knowledge intensive". It is more often based upon knowledge that is peculiar to specific contexts, and is therefore less amenable to generalized advice. In support of this, the FAO recently noted that "ecology-based knowledgeintensive farming systems... tend to rely on the observation and knowledge of ecosystem services much more than highexternal-input systems" [22]. This clearly highlights the importance of interaction and co-construction of knowledge as features of the role and design of any mobile-engaged knowledge systems.

M-Agri projects today tend to focus on value chain support rather than knowledge co-creation. Small farmers seeking to farm more sustainably need knowledge-intensive support systems. However, our analysis of Qiang et al's projects [23] shows that many of the existing services are less concerned with such "knowledge products", instead promoting value chain transactions. Nearly half of them focus on trade and direct support to the value chain (Fig.2), with knowledge related services (such as extension and education) accounting for only one third of projects.

\section{B. Telecoms Markets}

There has been a rapid growth in the use of mobile phones amongst the poor in recent years, with individual ownership now commonplace and access through friends and neighbours almost ubiquitous, even in countries with relatively low levels of mobile penetration. Increasingly, mobile service providers are offering deals that combine phone services with discounted or free access to specific data and internet services (e.g. Facebook). Such offers are making access to data services far more affordable, and alongside a general strengthening of ICT infrastructure this is driving increasing use of the internet amongst the poor. Usage amongst smallholder farmers remains constrained by a lack of awareness regarding applications, and low levels of information literacy. However, even with such constraints, growth in internet use is already evident.

Among a sample of M-Agri services reviewed in a World

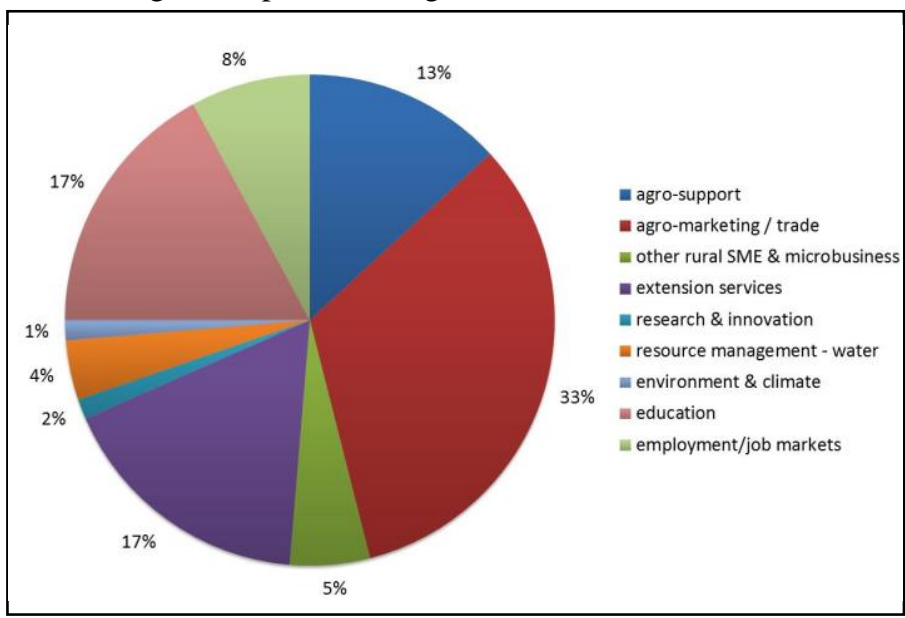

Figure 2 Breakdown of projects by service offering (based on an analysis of the 92 projects reviewed by Qiang et al [23])
Bank report [23] short message service (SMS) and voice were the preferred modes of communication within current projects (Fig.3). However, a nascent use of data dependent services was also evident.

GSMA have recently published a couple of reports that confirm how the industry is innovating in order to attract low income customers to engage with data services. One approach is through offering low cost, time based data packages that allow customers to use a fixed amount of data over a fixed time period - referred to as allowance based data 'sachets' [24]. They go on to highlight a trend for packages to offer cover shorter time periods, less than 24 hours.

They identify Facebook, Google, and Wikipedia as internet companies that are becoming active in attracting consumers in developing countries, and who have entered into partnerships with MNOs. This arrangement, known as 'zero-rating', bundles free use of internet services into a mobile phone package. They point out that access to these internet services is tailored to commonly accessible platforms such as SMS, and USSD. This is a particularly interesting development, as it confirms that even low-income consumers will have access to social networking services, which opens up all sorts of opportunities for peer-to-peer knowledge exchange among farmers.

The GSMA predict that sales of smartphones in emerging markets will overtake sales of feature phones at some point this year, and that the number of smartphones actually in use will exceed the number of feature phones in only a further 3 years i.e. by 2017 [25]. This means that although the number of services using multi-media functionality may be restricted by the types of devices currently found in people's pockets, this is going to change rapidly over the next few years.

Recent experience suggests that ICT-based projects (including M-Agri services) can take five years or more to move from conception to launch, so when developing such solutions, it is important to consider how technologies and their uses are likely to change over this kind of time horizon. To take an example, MPesa is often quoted as a fantastic innovation that has transformed the lives of Kenyans, and its growth from

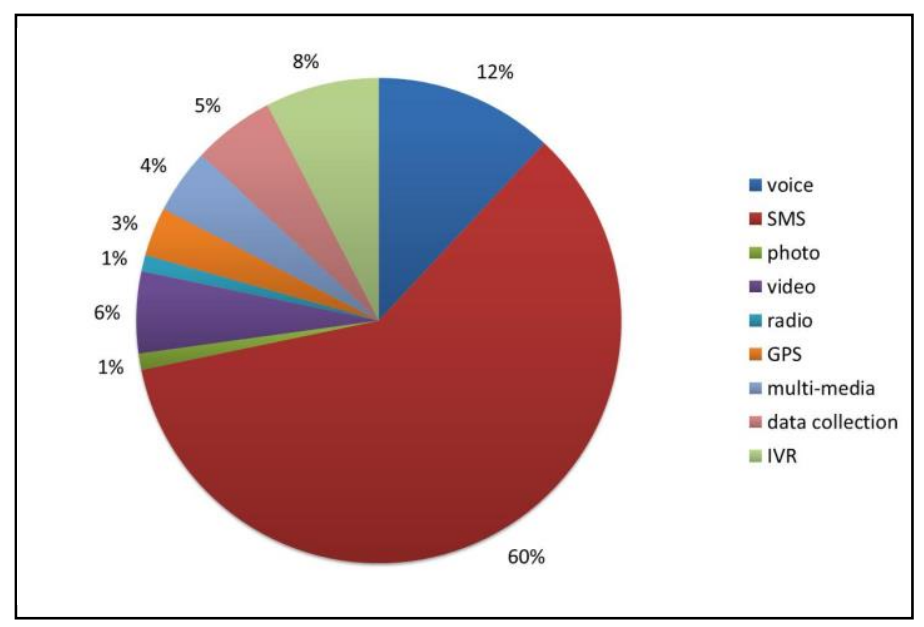

Figure 3 Breakdown of projects by principal technology used (based on an analysis of the 92 projects reviewed by Qiang et al [23]) 
launch to 6 million users is often cited as an indicator of the potential for ICT-based solutions to scale quickly. However, it took five years to move from the basic concept to a nationally launched product [26]. While a growing number of M-Agri projects are now being analysed in terms of their potential impact, there is still a need for much clearer analysis of what works, what doesn't, and why [26]. There have been a number of recent efforts established towards this end. This includes a series of comprehensive publications that have argued the case for ICT4D services both within and beyond the agricultural sector, such as the World Bank's Agriculture eSourcebook [27] and Maximising Mobile [28], the African Development Bank's eTransform Africa [30], the International Telecommunication Union's The Role of ICT in advancing growth in LDCs [31], and CTA's comprehensive Smart Toolkit for evaluation of information projects, products and services, which is specifically targeted at field practitioners in developing countries [32].

As trends in mobile phone usage shift towards an increasing demand for data rather than for voice calls alone, MNOs and others are beginning to focus on improving their provision of data services. Localised Wi-Fi systems and the extension of broadband services through the innovative exploitation of existing television-based infrastructure are two experiments in enhancing the availability of data services that have seen significant recent investment and some interesting outcomes. Alongside the development of such new infrastructures, which are beginning to facilitate more resilient and ever cheaper data flows, the use of audio and video files to provide agricultural instruction is also becoming increasingly feasible.

It is clear that significant changes are taking place in mobile access, usage and innovation amongst the BoP across developing countries, and that this will have direct relevance for the design of M-Agri services over the coming years.

\section{CONCLUSIONS}

Sustainable agriculture has several distinctive characteristics not found in conventional agriculture:

- Sustainable agriculture is not currently the dominant paradigm. As a result, support is needed at a political level to ensure that innovative efforts are not lost to the prevailing focus on improving productivity through the increased use of synthetic inputs. It is also not that well integrated into markets. While there are some value chains and markets that are based upon organic or ecological certification, for example, these certification schemes tend to focus on one aspect of the farming system in particular e.g. the minimisation of artificial inputs.

- Sustainable agriculture is knowledge intensive. Sustainable agricultural knowledge tends to be distributed and does not necessarily reside in western academia, making it difficult to capture and share. It can be extremely contextual and requires a deep understanding of the whole farming system. This means that it is relatively difficult to communicate or assimilate advice via bite-sized chunks.

- Components of understanding reside with professionals and farmers alike, requiring a coconstruction of knowledge. Individuals learn about complex systems by discussing them. While the general trend in agricultural extension is to encourage farmer-to-farmer learning, any initiative directed towards sustainable agriculture will need to utilise this insight more actively than conventional agricultural initiatives.

An actor-centric matrix is presented as a tool to assist with mapping of information flows and actors involved in the cocreation of knowledge. By highlighting gaps in information provision, and the strengths and weaknesses of different actors, the tool can help information service designers identify appropriate points for interventions.

Telecoms markets in emerging economies are already recognising the potential of data revenues from internet use, and access at the bottom of the pyramid to multimedia content through smartphones is expected to increase over the next few years. This presents exciting opportunities to overcome literacy barriers, and to use social media to enhance peer to peer communication that is crucial to the co-creation of knowledge on sustainable agriculture.

However, our main conclusion is that in the field of agriculture, ICT (and mobiles) are sustainability neutral; that is to say that ICT is equally applicable to the expansion of conventional high external-input-dependent agriculture, or to the development of more sustainable agro-ecological approaches. The rapid growth in mobile phone penetration in developing countries therefore presents a significant opportunity to help underpin a transformation in agricultural development and food systems, but without a co-operative and focused effort across different stakeholders groups - local actors, private sector partners, donors, expert institutions, and national governments - the potential for mobiles to empower sustainable agricultural development is unlikely to be maximized.

\section{REFERENCES}

[1] J.-M. Faurès and G. Santini, "Water and the Rural Poor. Interventions for improving livelihoods in sub-Saharan Africa," 2008.

[2] S. K. Lowder and B. Carisma, "Financial resource flows to agriculture investment," no. 11. 2011.

[3] S. Scherr, D. Nierenberg, C. Hebebrand, J. Shapiro, and K. Wheeler, "Food and agriculture : the future of sustainability," no. March 2012. p. 12, 2012.

[4] B. McIntyre, H. Herren, J. Wakhungu, and R. Watson, Agriculture at a Crossroads. International Assessment of Agricultural knowledge, Science and Technology for Development, 2009.

[5] B. Omilola, M. Yade, J. Karugia, and P. Chilonda, "Monitoring and assessing targets of the Comprehensive Africa Agriculture 
Development Programme (CAADP ) and the first Millennium Development Goal (MDG) in Africa," no. 31. 2010.

[6] FAO, "The state of food and agriculture 2010-11.," Aug. 2011.

[7] GSMA, "Women \& Mobile: a global opportunity," 2010.

[8] J. Daane, M. Blum, R. Rajalahti, D. Dolly, and E. Ruz, "The 'New Extensionist': roles, strategies, and capacities to strengthen extension and advisory services," 2012.

[9] B. E. Swanson and R. Rajalahti, "Strengthening agricultural extension and advisory systems: procedures for assessing, transforming, and evaluating extension systems." 2010.

[10] C. Manfre, D. Rubin, A. Allen, G. Summerfield, K. Colverson, and M. Akeredolu, "Reducing the gender gap in agricultural extension and advisory services: how to find the best fit for men and women farmers," no. May. 2013.

[11] Tanzania National Bureau of Statistics, "National sample census of agriculture. 2007/2008 Preliminary Report," 2010.

[12] S. Lokanathan and N. Kapugama, "Smallholders and microenterprises in agriculture: information needs and communication patterns," 2012.

[13] A. A. Jadhav, N. Pshenichnaya, and F. Smith, "Agricultural Value Added Services (Agri VAS): market entry toolkit.” p. 40, 2011.

[14] D. Souter, N. Scott, C. Garforth, R. Jain, O. Mascarenhas, and K. McKemey, "The economic impact of telecommunications on rural livelihoods and poverty reduction," 2005.

[15] GSMA, "Unlocking the potential: women and mobile financial services in emerging markets," 2013.

[16] D. Seth and D. Datta, "Teleuse@BOP4 BoP livelihoods and productive use of mobiles.," 2012.

[17] R. Samarajiva, "How the poor use ICTs: findings from multicountry studies of Teleuse at the Bottom of the Pyramid," no. April. Lirneasia, 2012.

[18] PWC, "Connected Life. The impact of the connected life over the next five years." GSMA, 2013.
[19] C. Foster, "ICTs and informal learning in developing countries." 2011.

[20] Yi. Zheng and R. Heeks, "Conceptualising information culture in Developing Countries." 2008.

[21] R. K. Bain, J. C. Tanner, D. Campbell, K. Lloyd-morgan, and F. Mburu, "The 'Wambui' Project. Final Technical Report. DFID Project R7425: Appropriate livestock extension," no. March. 2002.

[22] FAO, "Greening the Economy with Agriculture," 2012.

[23] C. Z. Qiang, S. C. Kuek, A. Dymond, and S. Esselaar, "Mobile applications for agriculture and rural development," 2012.

[24] GSMA, "Tailoring mobile internet tariffs for prepaid users - a balancing act," 2013.

[25] GSMA, "Mobile platform wars," 2014.

[26] S. Batchelor, "Changing the financial landscape of Africa: an unusual story of evidence-informed innovation, intentional policy influence and private sector engagement," IDS Bull., vol. 43, no. 5, pp. 84-90, Sep. 2012.

[27] R. Heeks, "The ICT4D 2.0 Manifesto: Where Next for ICTs and International Development?," Development Informatics Group. 2009.

[28] World Bank, ICT in agriculture: connecting amallholders to knowledge, networks, and institutions, no. 64605. World Bank, 2011, p. 424.

[29] World Bank, Information and communications for development 2012: Maximizing Mobile. World Bank, 2012.

[30] E. Yonazi, T. Kelly, N. Halewood, and C. Blackman, The Transformational Use of information and communication technologies in Africa. World Bank, 2012, p. 168.

[31] ITU, "The role of ICT in advancing growth in least developed countries.," 2011.

[32] CTA, KIT, and IICD, "Smart Toolkit for evaluating information projects, products and services," 2009. 